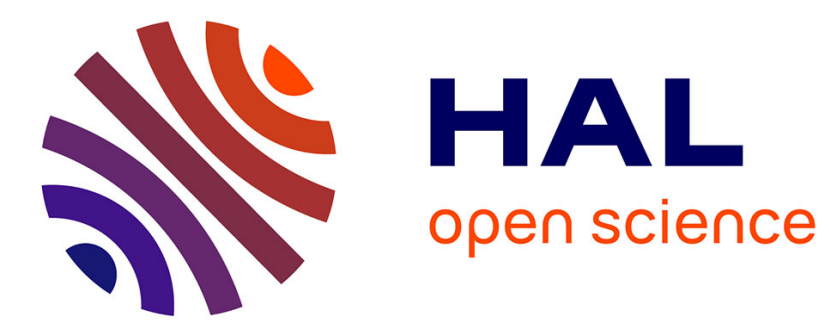

\title{
Practical Access to Aromatic Thiocyanates by CuCN-Mediated Direct Aerobic Oxidative Cyanation of Thiophenols and Diaryl Disulfides
}

Thomas Castanheiro, Mihaela Gulea, Morgan Donnard, Jean Suffert

\section{- To cite this version:}

Thomas Castanheiro, Mihaela Gulea, Morgan Donnard, Jean Suffert. Practical Access to Aromatic Thiocyanates by CuCN-Mediated Direct Aerobic Oxidative Cyanation of Thiophenols and Diaryl Disulfides. European Journal of Organic Chemistry, 2014, 2014 (35), pp.7814-7817. 10.1002/ejoc.201403279 . hal-01265876

\section{HAL Id: hal-01265876 \\ https://hal.science/hal-01265876}

Submitted on 18 Oct 2019

HAL is a multi-disciplinary open access archive for the deposit and dissemination of scientific research documents, whether they are published or not. The documents may come from teaching and research institutions in France or abroad, or from public or private research centers.
L'archive ouverte pluridisciplinaire HAL, est destinée au dépôt et à la diffusion de documents scientifiques de niveau recherche, publiés ou non, émanant des établissements d'enseignement et de recherche français ou étrangers, des laboratoires publics ou privés. 


\title{
Practical access to aromatic thiocyanates by CuCN-mediated direct aerobic oxidative cyanation of thiophenols and diaryl disulfides.
}

\author{
Thomas Castanheiro, Mihaela Gulea, ${ }^{*}$ Morgan Donnard* and Jean Suffert ${ }^{\star[a]}$
}

Dedicated to Pr Alexandre Alexakis on the occasion of his retirement

\begin{abstract}
We report a practical and mild aerobic oxidative CuCNmediated cyanation of thiophenols and diaryl disulfides. The reaction is performed under air at room temperature and reaches aromatic thiocyanates in moderate to good yields starting from a broad range of diversely functionalized substrates.
\end{abstract}

Organic thiocyanates are important synthetic intermediates for the preparation of various sulfur-containing compounds, such as thiols, sulfides, disulfides, thioesters, thiocarbamates, and sulfur heterocycles, and are also constituents of biologically active compounds. ${ }^{1}$ Compared to alkyl thiocyanates, which are generally easily avail-able from alkyl halides and potassium or ammonium thiocyanate, aryl thiocyanates are more difficult to access. Besides the synthetic applications mentioned above, aryl thiocyanates have been used as reagents for the cyanothiolation of alkynes. ${ }^{2}$ Two main strategies are currently used to prepare these compounds: the first one (path 1, Scheme 1) consists in the reaction of various non-sulfur aromatic substrates (arenes or aryl metal, aryl halides, aryl diazonium salts, or arylboronic acids) with a thiocyanating agent such as a thiocyanate salt or thiocyanogen. ${ }^{3}$ The second one (path 2, Scheme 1) is based on the nucleophilic attack of a cyanide (KCN, NaCN, or TMSCN) on a substrate bearing an electrophilic sulfur (aryl disulfides, aryl sulfenyl or sulfonyl derivatives). ${ }^{4}$ All these procedures require high temperatures or the presence of a metal catalyst, and the main drawback of the second strategy represents the use of highly toxic and moisture-sensitive cyanation agents. An additional approach making use of electrophilic $\mathrm{CN}$ sources has been developed but is infrequently used. ${ }^{5}$ Although CuCN was already used as the cyanide source for the formation of a C-CN bond ${ }^{6}$ and very recently for a N-CN bond, ${ }^{7}$ no example of sulfur cyanation by this reagent was described to date.

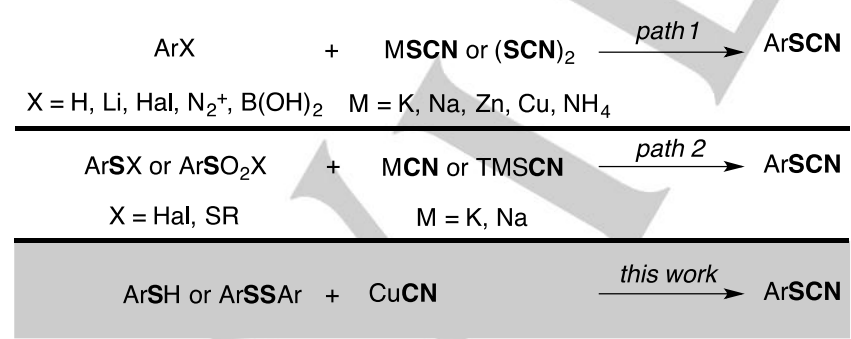

[a] Thomas Castenheiro, Dr. Mihaela Gulea, ${ }^{\star}$ Dr. Morgan Donnard and Dr. Jean Suffert ${ }^{\star}$

Université de Strasbourg, CNRS, Faculté de Pharmacie, Laboratoire d'Innovation Thérapeutique (UMR7200),

74 Route du Rhin, 67401 IIIkirch-Graffenstaden (France).

E-mail: gulea@unistra.fr, donnard@unistra.fr, jean.suffert@unistra.fr Webpage: http://somp.unistra.fr

Supporting information for this article is given via a link at the end of the document.
Scheme 1. Methods for the synthesis of aryl thiocyanates

Herein, we report an efficient S-cyanation of aromatic thiols and disulfides by $\mathrm{CuCN}$, at room temperature and using oxygen as oxidant ${ }^{8}$ (Scheme 1).

Preliminary studies were conducted on thiophenol 1a as a model substrate. Acetonitrile was chosen as solvent and molecular oxygen (air) as oxidant for obvious practical reasons. In first place we controlled if a ligand was required and no reaction was observed in the absence of it (Table 1 , entry 1 ). Then the influence of the copper ligand was evaluated (Table 1 , entries 2-7). Different usual ligands have been screened and it appeared that only two of them allowed the cyanation to take place, namely $\mathrm{N}$-methylimidazole and $N, N$ 'tetramethylethylenediamine (Table 1, entries 6 and 7). TMEDA turned out to be the best ligand as the reaction was complete after $18 \mathrm{~h}$ and thiocyanate 3a was obtained in a good $94 \%$ yield whereas $\mathrm{N}$-methylimidazole drove only to a poor $25 \%$ yield of the targeted compound along with a large amount of diphenyl disulfide $\mathbf{2 a}$. Ligands such as triphenylphosphine, acetylacetone, pyridine or 1,10-phenantroline were unable to promote the reaction and only disulfide $\mathbf{2} \mathbf{a}$, product of thiophenol oxidation, was recovered after $18 \mathrm{~h}$ reaction.

Table 1. Screening of ligands for the copper-mediated oxidative cyanation of thiophenol.

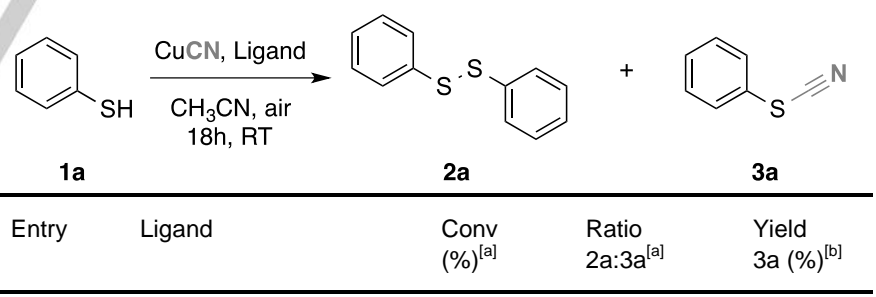

\begin{tabular}{lllll}
\hline 1 & No ligand & 0 & - & - \\
2 & $\mathrm{PPh}_{3}$ & 100 & $100: 0$ & - \\
3 & acetylacetone & 100 & $100: 0$ & - \\
4 & pyridine & 100 & $100: 0$ & - \\
5 & 1,10 -phenantroline & 100 & $100: 0$ & - \\
6 & $N$-methylimidazole & 100 & $54: 46$ & $25^{[\mathrm{c}]}$ \\
7 & TMEDA & 100 & $0: 100$ & 94 \\
\hline
\end{tabular}

[a] Determined by GC/MS analysis. [b] Isolated yield. [c] $83 \%$ based on recovered disulfide.

Conditions: 1 equiv. of thiophenol 1a, 2 equiv. of $\mathrm{CuCN}$ in $\mathrm{CH} 3 \mathrm{CN}(0.3 \mathrm{M})$ and 2 (bidentate) or 4 (monodentate) equiv. of ligand in an open vessel for $18 \mathrm{~h}$ at room temperature. 
Interestingly, it appeared that the full conversion of thiol 1a into disulfide 2a was almost instantaneous, presumably catalyzed by copper salts, and we envisioned that the reaction could be performed on the disulfide itself with an equivalent efficiency. It has been confirmed by the transformation of diphenyl disulfide $\mathbf{2 a}$ into thiocyanate $\mathbf{3} \mathbf{a}$ in a similar yield (88\%) as the reaction performed on thiophenol. Remarkably, we noticed that the use of sodium thiolate salts as substrate considerably accelerated the reaction. For example, sodium phenylthiolate was converted into thiocyanate $2 \mathrm{a}$ after $1 \mathrm{~h}$ in comparable yield (92\%). The effect of the solvent on the cyanation of diphenyl disulfide has been then investigated (Figure 1) and has been shown to be dramatic. Toluene, methanol, and 1,4-dioxane appeared incompatible with the reaction while $\mathrm{N}, \mathrm{N}$-dimethylformamide, tetrahydrofuran, and dichloromethane allowed the reaction to take place but drove after $18 \mathrm{~h}$ to the targeted thiocyanate $\mathbf{3 a}$ in modest yields (respectively $36 \%, 41 \%$ and $51 \%$ ).

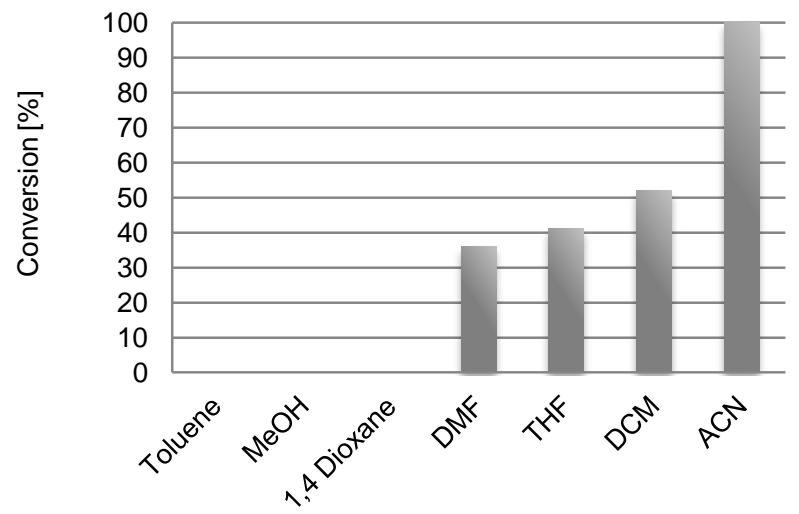

Figure 1. Relative efficiency of Copper-mediated oxidative cyanation of diphenyl disulfide in various solvents.

With the optimized conditions in hand, we investigated the scope of the reaction by performing the copper-mediated cyanation on representative aromatic thiols and diaryl disulfides (Scheme 2). Complete consumption of the disulfides was controlled after $18 \mathrm{~h}$ by GC/MS or TLC.

Methyl-substituted substrates such as $p$-tolylthiocyanate $\mathbf{3 b}$ and 2,4-dimethylthiocyanate $\mathbf{3 c}$ were synthesized in good yields of $74 \%$ and $71 \%$. Diversely chlorinated or fluorinated disulfides (2d, $2 \mathbf{e}$, and $\mathbf{2 f})$ furnished the desired thiocyanate in yields up to 95\% (4-fluorophenyl thiocyanate $\mathbf{3 e}$ ) while brominated ones $(\mathbf{2 g}$ and $1 \mathrm{~h}$ ) appeared less reactive, probably for electronic reasons, and drove to corresponding thiocyanates ( $\mathbf{g}$ and $\mathbf{3 h}$ ) in $40-50 \%$ yields. Electron-withdrawing substituents such as nitro group lower the reactivity of the disulfide, so disadvantaging the formation of the desired product. Thus, thiol 1i was cyanated into $3 \mathbf{i}$ in a poor $13 \%$ yield after $18 \mathrm{~h}$ at $80^{\circ} \mathrm{C}$ while only disulfide $2 \mathbf{i}$ was recovered when the reaction was performed at room temperature. Amide substituent appeared compatible with the transformation as thiol $\mathbf{1 I}$ was converted into thiocyanate $\mathbf{3} \mathbf{l}$ in reasonable $63 \%$ yield. However, we also demonstrated that the reaction was particularly sensitive to the steric hindrance of ortho substituents. Thus, substrates such as 2-bromo (2g) and 2-benzamide (2k) diphenyl disulfides gave the corresponding cyanated products in notably lower yields (37\% and $31 \%)$ than parent 4 -substituted compounds. So, thiols $\mathbf{1 h}$ and $\mathbf{1 l}$ gave $\mathbf{3 h}$ and $3 \mathrm{I}$ in $51 \%$ and $61 \%$ respectively.
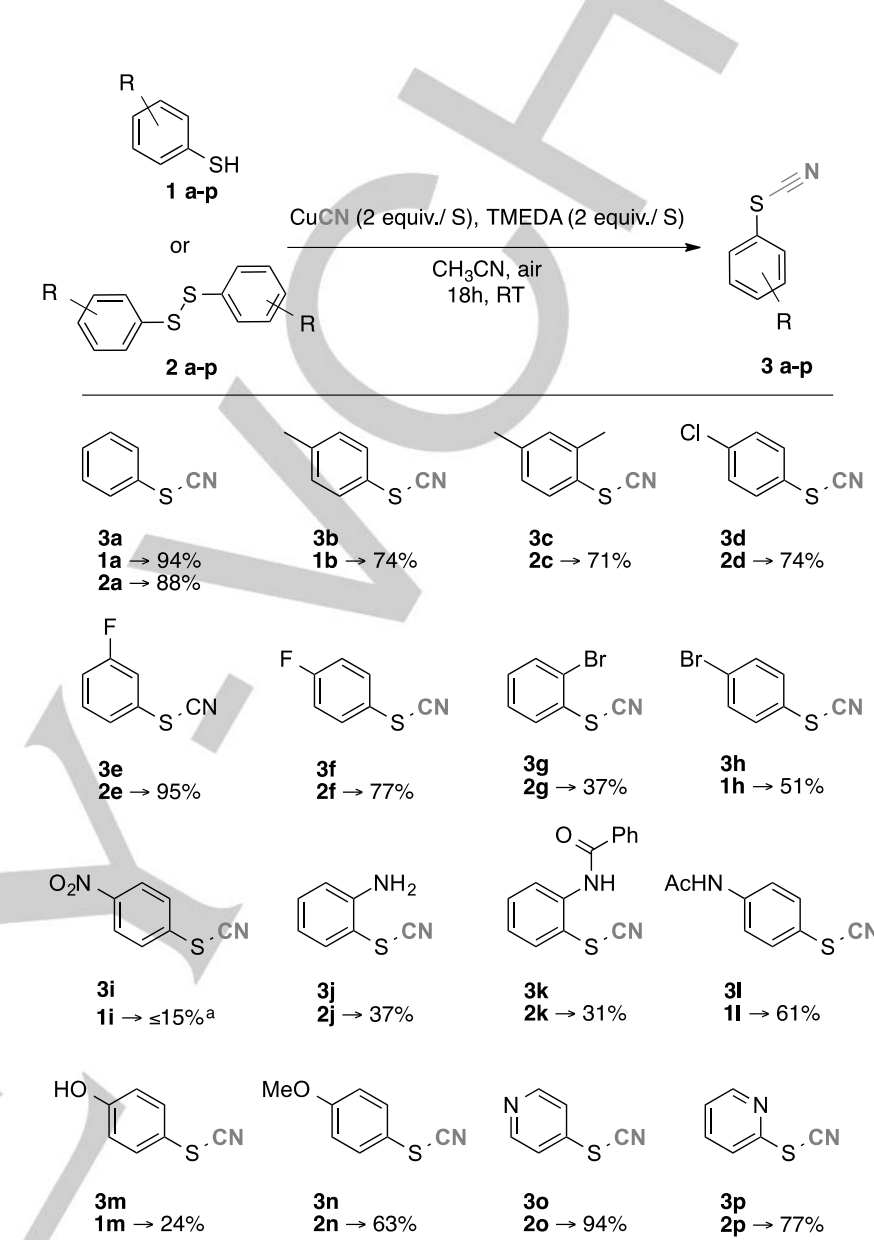

Conditions: 1 equiv. of thiol or 0.5 equiv. of diphenyl disulfide, 2 equiv. of $\mathrm{CuCN}$ in acetonitrile (0.3M) and 2 equiv. of TMEDA in an open vessel for $18 \mathrm{~h}$ at room temperature. ${ }^{[a]}$ Performed at $80^{\circ} \mathrm{C}$ for $18 \mathrm{~h}$; yield evaluated by NMR.

Scheme 2. Scope of copper-mediated cyanation of thiophenols and diaryl disulfides.

As expected, a free hydroxyl group on the substrate (1m) damaged the reaction $(3 \mathrm{~m}, 24 \%)$ while the corresponding 0 methylated derivative $1 \mathrm{n}$ gave good result (3n, 63\%). Gratifyingly, substrates bearing a pyridyl group ( 20 and $2 p$ ), that can unfavorably chelate copper species, were efficiently converted into thiocyanate 30 and $3 p$ in yields up to $94 \%$.

We propose a tentative mechanism based on experimental observation as well as reported mechanistic studies on copper chemistry with thiols..$^{9,10}$ The first step when starting from the thiol 1a is the complete conversion, almost instantaneously, into the corresponding disulfide $\mathbf{2} \mathbf{a}$ as demonstrated by a GC/MS analysis of the reaction mixture after $5 \mathrm{~min}$. Cuprous cyanide could then perform an oxidative addition into the S-S bond to form copper(III) intermediate $4 a$ that could undergo a reductive elimination in order to furnish the desired thiocyanate $\mathbf{3} \mathbf{a}$ as well 
as copper(I) thiolate 5a. To finish, two molecules of this $\mathrm{Cu}(\mathrm{I})$ salt could generate under aerobic conditions a molecule of disulfide 2a along with copper oxide species (observed black powder).

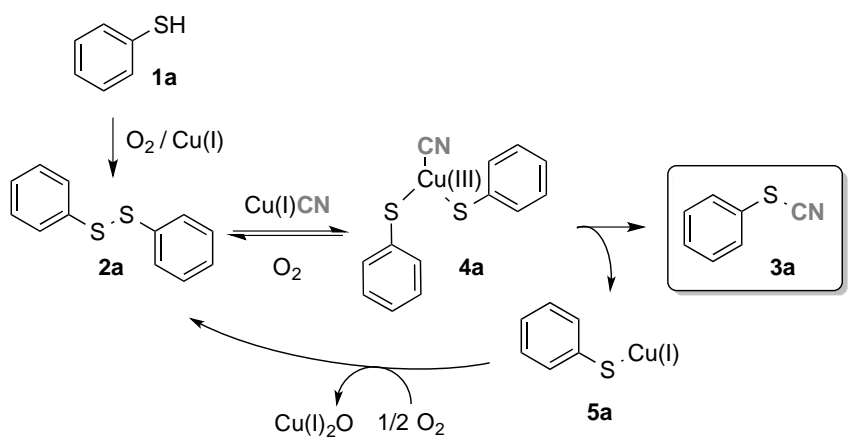

Scheme 3. Plausible reaction pathway.

In conclusion, we have developed a practical and mild copper-mediated cyanation of thiophenols and diaryl disulfides. The reaction uses convenient cuprous cyanide as $\mathrm{CN}$ source and is performed under air at room temperature, leading readily to variously functionalized aromatic thiocyanates in moderate to very good yields. TMEDA and $N$-methylimidazole have been determined as efficient promoters of the reaction and acetonitrile as the best solvent. This method represents an interesting complement to existing syntheses of thiocyanates with synthetic potential use in practical oxidative cyanation reaction. At the present time, further studies are under investigations in order to elucidate the mechanism of this transformation and to extend the scope of this approach to different valuable substrates.

\section{Experimental Section}

General procedure: To a solution of TMEDA $(0.3 \mathrm{ml}, 2 \mathrm{mmol})$ in acetonitrile $(3 \mathrm{ml})$ was added $\mathrm{CuCN}(179 \mathrm{mg}, 2 \mathrm{mmol})$ and then the disulfide $(0.5 \mathrm{mmol})$ or the thiophenol $(1 \mathrm{mmol})$. The reaction was stirred overnight, at room temperature, under air. The reaction mixture was then filtered through celite pad. The filtrate was evaporated and the crude product was directly purified on silica gel column, or was washed with water and the product extracted with diethyl ether. The product was purified by flash chromatography (heptane/ ethyl acetate).

Supporting Information: (see footnote on the first page of this article): All experimental procedures, characterization data, and copies of the ${ }^{1} \mathrm{H}$ NMR, ${ }^{13} \mathrm{C}$ NMR.

\section{Acknowledgements}

The CNRS (Centre National de la Recherche Scientifique) and the University of Strasbourg (IDEX PhD grant for T.C.) are acknowledged for financial support. The authors are grateful to Dr. Patrick Wherung from the "Plateforme d'Analyse Chimique Strasbourg Illkirch (PACSI)" for valuable help with HRMS analyses.
Keywords: thiocyanate $\cdot$ copper $\bullet$ aerobic oxidative coupling $•$ disulfide $\cdot$ cyanation

[1] For a review, see: A. W. Erian, S. M. Sherif, Tetrahedron 1999, 55 7957-8024. For selected papers, see: a) I. W. J. Still, D. F. Toste, J. Org. Chem. 1996, 61, 7677-7680; b) Z. P. Demko, B. K. Sharpless, Org. Lett. 2001, 3, 4091-4094; c) S. A. Laufer, A. J. Liedtke, Tetrahedron Lett. 2006, 47, 7199-7203; d) T. Billard, B. R. Langlois, M. Medebielle, Tetrahedron Lett. 2001, 42, 3463-3465; e) P. Garcia, Y. Evanno, P. George, M. Sevrin, G. Ricci, M. Malacria, C. Aubert, V. Gandon, Chem. Eur. J. 2012, 18, 4337-4344; f) F. Ke, Y. Qu, Z. Jiang, Z. Li, D. Wu, X. Zhou, Org. Lett. 2011, 13, 454-457; g) V. V. Sureshbabu, B. Vasantha, H. P. Hemantha, Synthesis 2011, 1447-1455; h) M. Piekutowska, Z. Pakulski, Tetrahedron Lett. 2007, 48, 8482-8486; h) Z. Zhang, L. S. Liebeskind, Org. Lett. 2006, 8, 4331-4333; i) M. A. K. Zarchi, E. Nahid, Phosphorus Sulfur Silicon Relat. Elem. 2012, 187, 1226-1235.

[2] a) I. Kamiya, J. Kawakami, S. Yano, A. Nomoto, A. Ogawa, Organometallics 2006, 25, 3562-3564; b) T. Ozaki, A. Nomoto, I. Kamiya, J. Kawakami, A. Ogawa, Bull. Chem. Soc. Jpn. 2011, 84, 155163; c) Y. T. Lee, S. Y. Choi, Y. K. Chung, Tetrahedron Lett. 2007, 48, 5673-5677; d) W. X. Zheng, A. Ariafard, Z. Y. Lin, Organometallics 2008, 27, 246-253.

[3] See for selected examples: a) J. H. Clark, C. W. Jones, C. V. A. Duke, J. M. Miller, J. Chem. Soc. Chem. Commun. 1989, 81-82; b) K. Takagi, H. Takachi, K. Sasaki, J. Org. Chem. 1995, 60, 6552-6556; c) Y.-F. Wang, Y. Zhou, J.-R. Wang, L. Liu, Q.-X. Guo, Chin. Chem. Lett. 2006 17, 1283-1286; d) I. P. Beletskaya, A. Sigeev, A. S. Peregudov, P. V. Petrovskii, Mendeleev Commun. 2006, 5, 250-251; e) M. HosseiniSarvari, M. Tavakolian, J. Chem. Research 2008, 6, 318-321; f) A Batool, A.-R. Pourali, M. Rahmani, Synth. Commun. 2012, 42, 11841191; g) N. Sun, H. Zhang, W. Mo, B. Hu, Z. Shen, X. Hu, Synlett, 2013, 24, 1443-1447.

[4] See for selected examples: a) I. W. J. Still, I. D. G. Watson, Synth Commun. 2001, 31, 1355-1359; b) S. Kagabu, K. Sawahara, M. Maehara, S. Ichihashi, K. Saito, Chem. Pharm. Bull. 1991, 39, 784-785; c) S. Kagabu, M. Maehara, K. Sawahara K. Saito, J. Chem. Soc., Chem. Commun. 1988, 1485-1486; d) D. N. Harpp, B. T. Friedlander, R. A. Smith, Synthesis, 1979, 181-182; e) R. A. Gancarz, J. L. Kice, J. Org. Chem. 1981, 46, 4899-4906; f) A. Patchornik, Y. Degani, H. Neumann, J. Am. Chem. Soc. 1970, 92, 6969-6971; g) H. Guangdian, W. Hongyan, Chinese Chem. Lett. 1999, 2, 843-844.

[5] Representative examples: a) Y.-Q. Wu, D C. Limburg, D. E. Wilkinson, G. S. Hamilton Org. Lett. 2000, 2, 795-797; b) J.-J. Kim, D.-H. Kweon, S.-D. Cho, H.-K. Kim, E.-Y. Jung, S.-G. Lee, J. R. Falck, Y.-J. Yoona Tetrahedron 2005, 61, 5889-5894; c) L. Montanari, F. Pavanetto, T. Modena, M. Mazza Farmaco - Ed. Sci. 1984, 39, 935-944

[6] For selected papers, see: a) K. W. Rosenmund, E. Struck, Chemische Berichte 1919, 52, 1749-1756; b) J. von Braun, G. Manz, Liebigs Ann. Chem. 1931, 488, 111-126; c) N. K. Swamy, A. Yazici, S. G. Pyne, J. Org. Chem. 2010, 75, 3412-3419; d) D. Wang, L. Kuang, Z. Li, K. Ding, Synlett 2008, 69-72; e) R. S. Reddy, P. K. Prasad, B. B. Ahuja, A. Sudalai, J. Org. Chem. 2013, 78, 5045-5050; f) G. Zhang, L. Zhang, M. Hu, J. Cheng, Adv. Synth. Catal. 2011, 353, 291-294; g) C. C. Silveira, V. Caliari, A. S. Vieira, S. R. Mendes, J. Braz. Chem. Soc. 2007, 18, 1481-1485; h) T. Schareina, M. Beller in Copper-Mediated CrossCoupling Reactions, (Eds.: G. Evano, N. Blanchard), John Wiley \& Sons, Hoboken, New Jersey, 2014, pp. 3133-334.

[7] a) F. Teng, J.-T. Yu, Y. Jiang, H. Yang, J. Cheng, Chem. Commun. 2014, 50, 8412-8415; b) M. Donnard, J. Suffert, Presented at the $15^{\text {th }}$ French-American Chemical Society (FACS) symposium, Avignon, France, June 1-5, 2014.

[8] Representative recent examples of carbon-heteroatom coppermediated oxidative coupling: a) P. Y. S. Lam, C. G. Clark, S. Saubern, J. Adams, M. P. Winters, D. M; T. Chan, A. Combs, Tetrahedron Lett. 1998, 39, 2941-2944; b) D. A. Evans, J. L. Katz, T. R. West, 
Tetrahedron Lett. 1998, 39, 2937-2940; c) Y. Bolshan, R. A. Batey Angew. Chem. Int., 2008, 47, 2109-2112; d) T. Hamada, S. S. Stahl, J. Am. Chem. Soc. 2008, 130, 833-835; e) D. J. Winternheimer, C. A. Merlic, Org. Lett. 2010, 12, 2508-2510; f) (1) K. Jouvin, J. Heimburger, G. Evano, Chem. Sci. 2012, 3, 756-760; g) G. Evano, K. Jouvin, C Theunissen, C. Guissart, A. Laouiti, C. Tresse, J. Heimburger, Y. Bouhoute, R. Veillard, M. Lecomte, A. Nitelet, S. Schweizer, N. Blanchard, C. Alayrac, A.-C. Gaumont, Chem. Commun. 2014, 50, 10008-10018.

[9] For a review on C-S metal-catalyzed cross-coupling reactions, see: I. P. Beletskaya, V. P. Ananikov, Chem. Rev. 2011, 111, 1596-1636.

[10] For mechanisms of copper-induced reactions involving thiols or disulfides, see for selected examples: a) C. Savarin, J. Srogl, L. S. Liebeskind, Org. Lett. 2002, 4, 4309-4212; b) A. Varela-Álvarez, L. S. Liebeskind, D. G. Musaev, Organometallics 2012, 31, 7958-7968; c) C Chen, Z. Weng, J. F. Hartwig, Organometallics 2012, 31, 8031-8037; d) N. Taniguchi, T. Onami, J. Org. Chem. 2004, 69, 915-920. 
Entry for the Table of Contents (Please choose one layout)

Layout 2:

\section{SHORT COMMUNICATION}<smiles>Sc1ccccc1</smiles>

or<smiles>[R]c1cccc(SC)c1</smiles><smiles>Oc1ccccc1</smiles><smiles>N#Cc1ccccc1S</smiles>

Yield up to $94 \%$

A practical and mild aerobic oxidative $\mathrm{CuCN}$-mediated cyanation of thiophenols and diaryl disulfides is reported. The reaction is performed under air at room temperature and reaches aromatic thiocyanates in moderate to good yields starting from a broad range of diversely functionalized substrates.

Thomas Castanheiro, Mihaela Gulea, * Morgan Donnard ${ }^{*}$ and Jean Suffert*

Page No. - Page No.

Practical access to aromatic thiocyanates by CuCN-mediated direct aerobic oxidative cyanation of thiophenols and diaryl disulfides. 